\title{
Ionospheric temporal and spatial variations during the 18 August 2003 storm over China
}

\author{
Debao Wen ${ }^{1,2}$, Yunbin Yuan ${ }^{1}$, Jikun $\mathrm{Ou}^{1}$, Xingliang Huo ${ }^{1,2}$, and Kefei Zhang ${ }^{3}$ \\ ${ }^{1}$ Institute of Geodesy and Geophysics, Chinese Academy of Sciences, Wuhan 430077, China \\ ${ }^{2}$ Graduate School of Chinese Academy of Sciences, Beijing, 100039, China \\ ${ }^{3}$ School of Mathematical and Geospatial Sciences, RMIT University, Australia
}

(Received September 1, 2006; Revised November 23, 2006; Accepted December 18, 2006; Online published May 7, 2007)

\begin{abstract}
The effects of the 18 August 2003 geomagnetic storm on the ionosphere over China have been first studied by combining dual-frequency Global Positioning System (GPS) observation data from the Crustal Movement Observation Network of China (CMONOC) using the computerized ionospheric tomography (CIT) technique. The temporal and spatial variations of the ionosphere are analyzed using a time series of ionospheric electron density (IED) maps, and the ionospheric storm evolution process is revealed. The tomographic results show that the main ionospheric effects of this storm over China are: (1) that positive storm phase effects usually happen in the low-latitude ionosphere, (2) that negative storm phase effects occur in the mid-latitude ionosphere, and (3) that the equatorial anomaly structure can also be found. In contrast to the quiet period of the ionosphere on 17 August 2003, the equatorial anomaly crest moved to the north in the main phase of the storm and then moved back to the original location in the recovery phase on 19 August 2003. We compared the peak density $\mathrm{N}_{\mathrm{m}} \mathrm{F}_{2}$ and the peak height $\mathrm{h}_{\mathrm{m}} \mathrm{F}_{2}$ obtained from the ionosonde observations at Wuhan station and those inverted by the CIT technique to confirm the reliability of the GPS-based tomographic technique. The tomographic results revealed that the GPS-based CIT technique can be used to monitor large-scale ionospheric disturbances during geomagnetic storms.
\end{abstract}

Key words: GPS, ionospheric electron density, computerized ionospheric tomography, geomagnetic storm.

\section{Introduction}

Substantial signal delays are expected when satellite radio signals traverse through the ionosphere due to the dispersive nature of the ionosphere. The amount of the delay is proportional to the line integral of ionospheric electron density (IED) along the ray path from a satellite to a receiver. In addition to the propagation delay, the dynamics of ionospheric heterogeneous structure may produce phase fluctuations which can potentially impact on the propagation of radio signals and degrade the performance of satellite navigation systems (Yang and Zhang, 2005). During geomagnetic storms, ionospheric irregularities are strengthened in amplitude and may cause signal degradation (Yizengaw et al., 2005). Therefore, it is necessary to study the effects of geomagnetic storms on the ionosphere and investigate ionospheric effects on our living environment during geomagnetic storms. The effects of geomagnetic storms on the ionosphere have been studied for many years. In the past, only limited ground observations, such as ionosondes and incoherent scatter radar data from a few locations, were used to investigate the disturbed characteristics of the ionosphere under geomagnetic storms condition (Yin and Mitchell, 2005). However, using this approach, it is difficult to obtain large-scale ionospheric variations during geomag-

Copyright (c) The Society of Geomagnetism and Earth, Planetary and Space Sciences (SGEPSS); The Seismological Society of Japan; The Volcanological Society of Japan; The Geodetic Society of Japan; The Japanese Society for Planetary Sciences; TERRAPUB. netic storms. Since geomagnetic storms have global effects, it is necessary to apply global observations to study the large-scale disturbed performance of the ionospheric structure during geomagnetic storms.

The advent of satellite navigation technology (e.g. Global Positioning System; GPS) provides the potential for investigating both temporal and spatial variations of the ionosphere on a large scale. Ionospheric total electron content (TEC) derived from GPS data has long been an important means of studying the ionospheric disturbance under geomagnetic storms environments. However, it cannot be applied to study the vertical disturbed structure of the ionosphere because the ionosphere is modeled in a two-dimensional manner. Since Austen et al. (1986) first proposed the computerized ionospheric tomography (CIT) technique, it has become a popular and successful tool of studying the ionosphere. Using this approach, some researchers have applied low-orbit satellites (e.g. Navy Navigation Satellite System) observations to reconstruct the ionospheric structure over a fixed longitude chain (Raymund et al., 1990; Kunitsyn et al., 1995; Pryse et al., 1998). However, the reconstructed image of the ionosphere is only two-dimensional in nature. Kunitsyn (1997) first confirmed the feasibility of applying the CIT technique to reconstruct the three-dimensional structure by using high-orbit satellite systems such as GPS. The GPS-based CIT has since also been applied to study the ionospheric response to geomagnetic storms (Hernandez-Pajares et al., 1998; Bust et al., 
2000; Yin et al., 2004, 2005; Yizengaw et al., 2005; Yuan et al., 2005; Wen et al., 2007).

In this paper, dual-frequency GPS data from the Crustal Movement Observation Network of China (CMONOC) are used to investigate the ionospheric response to the geomagnetic storm on 18 August, 2003. A tomographic reconstruction of IED is performed to study the altitude-latitudedependent dynamics throughout the storm. The dynamic variations of the ionosphere during the geomagnetic storm are analyzed and discussed in details based on the time series of the inverted IED during the geomagnetic storm. Both $\mathrm{N}_{\mathrm{m}} \mathrm{F}_{2}$ and $\mathrm{h}_{\mathrm{m}} \mathrm{F}_{2}$ obtained from the ionosonde observations at Wuhan station are shown for a comparison with those obtained through an inversion using the CIT technique. The comparison results also confirm the reliability of GPS-based tomographic results.

\section{The CIT Technique}

The CIT technique applies slant TEC (STEC) to invert IED. However, ionospheric STEC is a line integral of electron densities along the ray path from satellite to receiver. To simplify IED inversion, the imaged region of the ionosphere is first discretized into numerous small pixels in a selected reference frame. Within each pixel, the electron density can be assumed to be constant, and the ray path length within each pixel can be determined for each ray. Given the STEC measurements $y$, the CIT problem may be expressed as:

$$
y_{m \times 1}=A_{m \times n} x_{n \times 1}+e_{m \times 1}
$$

where $n$ is the number of pixels in the image, $m$ is the number of STEC measurements, $y$ is a column vector of the $m$ known STEC measurements, $A$ is an $m \times n$ matrix with $A_{i j}$ being the length of ray $i$ traversing through pixel $j, x$ is a column vector consisting of all the unknown electron densities parameters in all pixels, and $e$ is a column vector associated with the discretization errors and measurement noises.

Before the CIT technique is implemented, GPS data preprocessing is first performed to detect and remove or correct outliers and cycle slips by using the algorithms described by Blewitt (1990). To calculate the STEC, GPS pseudoranges (P2-P1) and carrier phases (L1-L2) are applied to form an efficient ionospheric combination (Blewitt, 1990). Taking the receiver and satellite differential group delay biases into account, the derived STECs should be precalibrated. In this work, a new scheme is devised to cope with the above biases. Firstly, the satellite and receiver instrumental biases over the three days $(17,18$, and $19 \mathrm{Au}-$ gust 2003) were determined using the method described by Yuan and Ou (1999), then the mean values of the instrumental biases over the three days were computed. These were subsequently applied to calibrate each of the differential delay for each satellite-receiver pair during the $18 \mathrm{Au}-$ gust 2003 storm. Secondly, the bias-corrected differential delays are applied to calibrate the differential phases of the storm day by using a least squares fitting method. Thus, the absolute STECs were determined from the differential phase and time delays recorded during the storm.

GPS pseudoranges of low elevation angle satellites are sensitive to multipath effects: in general, the lower the el- evation angle, the larger the multipath error. On the other hand, GPS data obtained at low elevation angles are important for getting some information about the vertical distribution of the IED. Hence, a crucial problem is how to select a proper cut-off elevation angle for the CIT technique. A large cut-off elevation angle reduces the vertical resolution of the inverted results; a small elevation angle reversely affects the accuracy of the IED inversion. In this work, an elevation cut-off angle of $10^{\circ}$ is adopted.

The sample interval of GPS data is $30 \mathrm{~s}$. The data is partitioned into a series of half-hour sets. To compensate for the insufficiency of ground-based GPS data, an IRI model-assisted three-dimensional CIT technique is used. In this technique, the image region is represented as a threedimensional array of pixels, and a set of initial IED values obtained from IRI model is added to the corresponding pixel. A time series of the IED maps is then reconstructed using the algebraic reconstruction algorithm in which the initial IED value of each pixel is improved in an iterative mode. The resulting images extended latitudinally from $10^{\circ} \mathrm{N}$ to $55^{\circ} \mathrm{N}$ and longitudinally from $70^{\circ} \mathrm{E}$ to $140^{\circ} \mathrm{E}$. The altitude ranges are from 100 to $1000 \mathrm{~km}$.

\section{Reconstructed Results and Analysis}

A moderately severe geomagnetic storm event occurred on 18 August 2003. The Storm Sudden Commencement (SSC) occurred at 14:21UT on 17 August 2003. During this storm, the planetary geomagnetic activity indices KP reached extreme values of $\sum^{K p=52+}$. The $3-\mathrm{h} \mathrm{KP}$ is enhanced from the middle of 17 August and reached $7+$ at 18:00UT on 18 August 2003. The minimum Disturbance Storm-time (Dst) value reached $-168 \mathrm{nT}$ at 16:00 UT.

Figure 1 shows the variations in the IED with altitude and latitude at 13:00UT during the magnetically active period on 18 August 2003 and magnetically quiet period on 17 and 19 August 2003. Comparing Fig. 1(a) with Fig. 1(b), one can see that the IED in the $\mathrm{F}$ region was enhanced between $10^{\circ} \mathrm{N}$ and $35^{\circ} \mathrm{N}$ during the geomagnetic storm on 18 August 2003 and that positive storm phase effects appeared. The IED maximum enhancement reached $260 \%$ between $15^{\circ} \mathrm{N}$ and $25^{\circ} \mathrm{N}$. However, the negative storm phase effect of the ionosphere appeared latitudinally from $35^{\circ} \mathrm{N}$ to $55^{\circ} \mathrm{N}$ and altitudinally from 200 to $600 \mathrm{~km}$ above the ground, and then the positive storm phase effect also appeared latitudinally from $35^{\circ} \mathrm{N}$ to $55^{\circ} \mathrm{N}$ and altitudinally from 600 to $800 \mathrm{~km}$. The reconstructed results show that the storm phase effects are not only latitude-dependent but also height-dependent. Similar characteristics of the geomagnetic storm can also be found in other time periods. Figure 1(b) shows that a disturbed structure of the ionosphere over China occurred on 18 August 2003. At the same time, one can see that the ionospheric equatorial anomaly still existed and that the equatorial anomaly crest moved to $27^{\circ} \mathrm{N}$; the crest of the anomaly structure then moved back to the original locations at 13:00 UT on 19 August 2003 (Fig. 1(c)).

A large increase in IED values and a large northward expansion of the equatorial ionization anomaly (EIA) imply that a very large equatorial fountain effect has occurred; this may be due to an eastward electric field which penetrated from high to low latitudes and lifted the ionosphere layers 

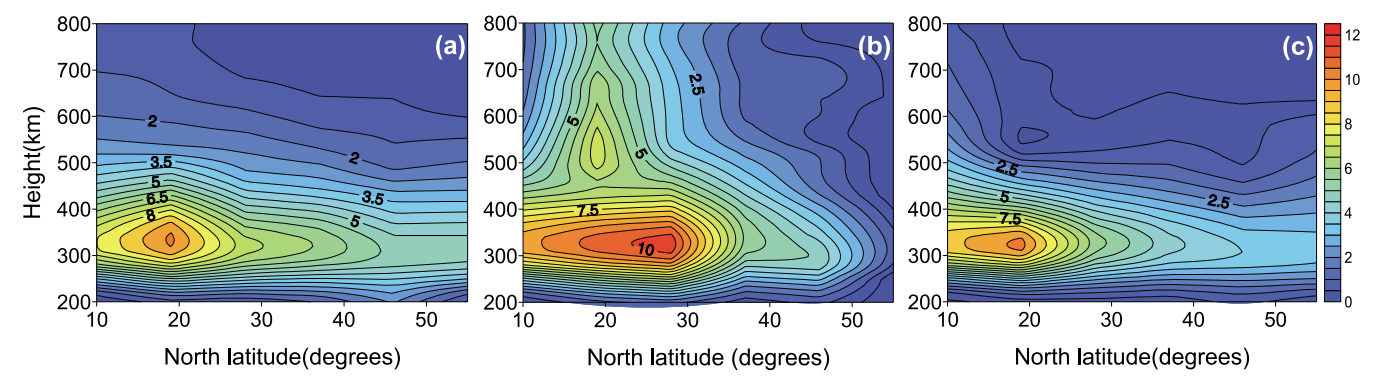

Fig. 1. Two-dimensional images of IED over China at 13:00UT (21:00 local time (LT)) on magnetic quiet days (Figs. 1(a) and (c)) and on the magnetic storm day (Fig. 1(b)). (a) 17 August 2003, (b) 18 August 2003, (c) 19 August 2003. The unit of electron density is $10^{11} \mathrm{e} / \mathrm{m}^{3}$.
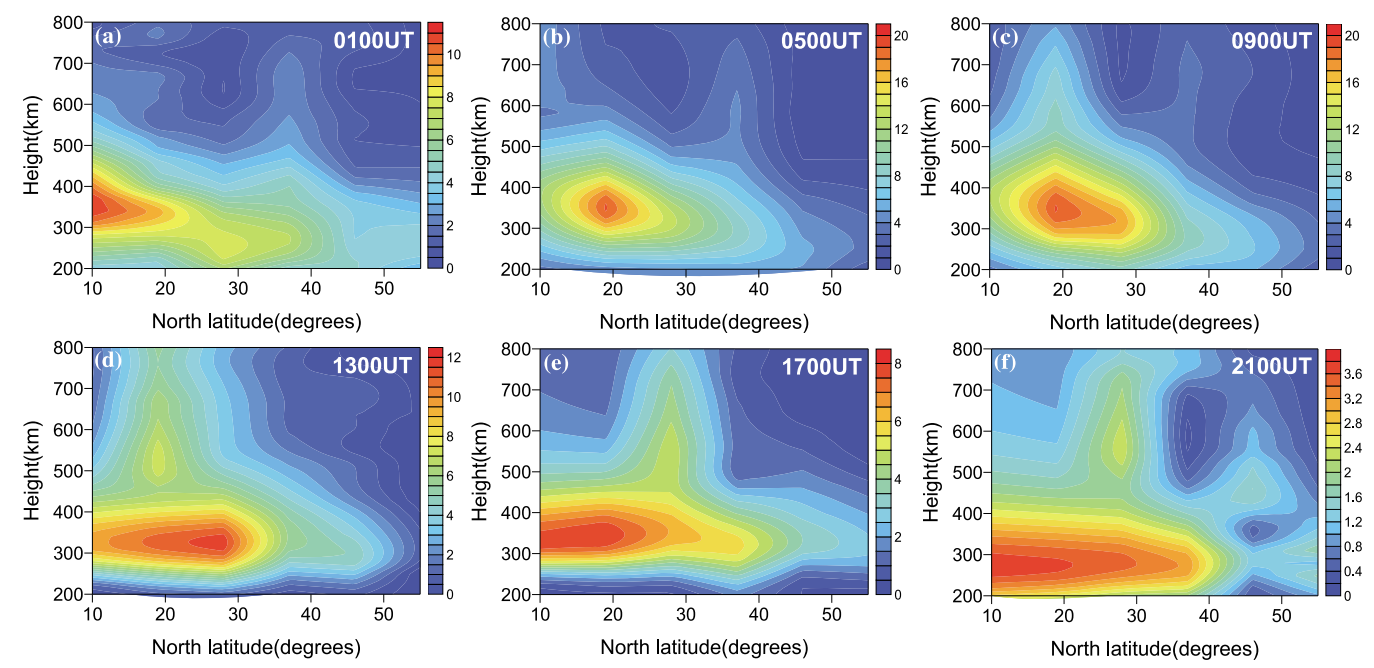

Fig. 2. Samples of IED distribution inverted for 18 August 2003. Each subfigure represents the corresponding electron density reconstructed in different universal times (universe time plus $8 \mathrm{~h}$ is local time), which are labeled at the top right corner of the subfigure. The unit of electron density is $10^{11}$ $\mathrm{e} / \mathrm{m}^{3}$.

through a strong upward $E \times B$ drift. Suppression of the equatorial anomaly observed during the recovered phase of the storm may be associated with downward $E \times B$ drifts (Lin et al., 2005, and references therein).

Figure 2 shows the examples of typical tomographic images of the ionosphere over China during the magnetically active periods on 18 August 2003, at a longitude chain of $114^{\circ} \mathrm{E}$. The numbers in the top right corner represent universal time. The evolution of the disturbed structure of the ionosphere over China can be clearly seen in the series of GPS-based CIT images presented in Fig. 2. The first panel (Fig. 2(a)), which was obtained from data recorded between 00:30 and 01:00 UT, shows a clear disturbed structure between $30^{\circ} \mathrm{N}$ and $40^{\circ} \mathrm{N}$. Average F-layer peak density altitude is about $340 \mathrm{~km}$ at this time. The same disturbed structure can also be found at the identical geographic position in the second panel (Fig. 2(b)), but its intensity is strengthened in contrast to Fig. 2(a). However, a new disturbed structure of the ionosphere can be seen to have occurred between $12^{\circ} \mathrm{N}$ and $27^{\circ} \mathrm{N}$ in the third panel (Fig. 2(c)). The original disturbed structure of the ionosphere existed as well, but its intensity was weakened. In Fig. 2(d), the disturbed structure of the ionosphere, which occurs between $30^{\circ} \mathrm{N}$ and $40^{\circ} \mathrm{N}$ in Fig. 2(a)-(c) disappeared completely, but the other disturbed structure which occurs between $12^{\circ} \mathrm{N}$ and $27^{\circ} \mathrm{N}$ in Fig. 2(c) still appeared. From the above tomographic images, one can see that the equatorial anomaly structure exists. It can also be seen that the disturbed structure occurring in Fig. 2(d) moved to the north, reaching the geographic range between $20^{\circ} \mathrm{N}$ and $35^{\circ} \mathrm{N}$ in Fig. 2(e, f) and that the equatorial anomaly structure does not occur. The average F-layer peak density altitude fell to $285 \mathrm{~km}$ during the period 20:30-21:00 UT, and a new disturbed structure appeared between $40^{\circ} \mathrm{N}$ and $50^{\circ} \mathrm{N}$. This could be a very interesting mid-latitude ionospheric response to the storm and worthy of further study. Meanwhile, the IED reached the minimum value during this time period.

As the time evolves, it can be seen that the values of the inverted IED in Fig. 2 vary from small to large at first, and then from large to small; this observation agrees with the normal change laws in daytime and nighttime over China and the fact that the characteristics of the IED depend mainly on the dark solar activity. Figure 2 reveals that there are large differences between the characteristics of the IED in mid-latitude and low-latitude areas and that the IED values over northern China are smaller than those over southern China on the whole. This indicates fact that there is a strong correlation of the variation of IED with latitude.

Vertical resolution of the CIT technique is usually very limited because of the absence of horizontal ray paths from GPS satellites to ground receivers. To validate the reliabil- 


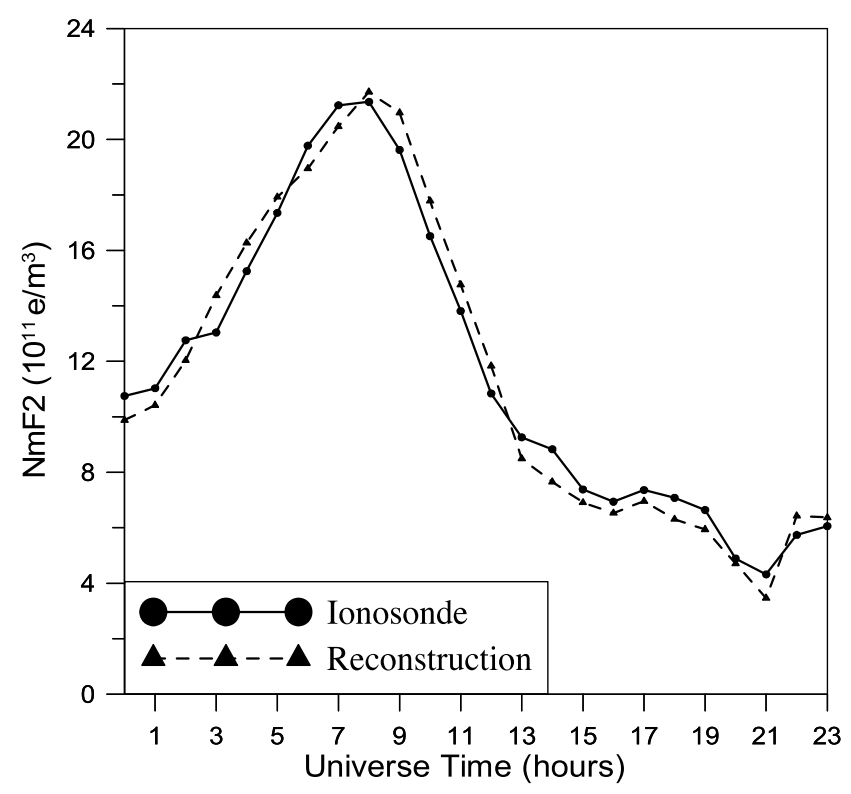

Fig. 3. Comparison of the $\mathrm{N}_{\mathrm{m}} \mathrm{F}_{2}$ values obtained from the GPS-based CIT reconstruction and those from ionosonde data recorded at Wuhan station.

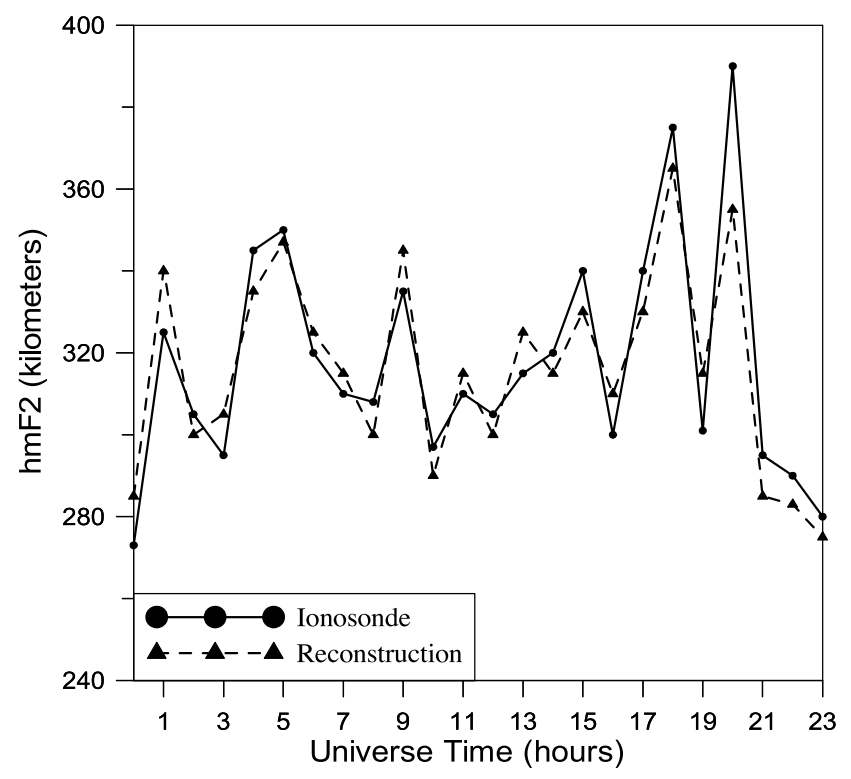

Fig. 4. Comparison of the $\mathrm{h}_{\mathrm{m}} \mathrm{F}_{2}$ values obtained from the GPS-based CIT reconstruction and those from ionosonde data recorded at Wuhan station.

ity of the vertical resolution of an IRI model-assisted GPSbased CIT, we obtained both the $\mathrm{N}_{\mathrm{m}} \mathrm{F}_{2}$ and $\mathrm{h}_{\mathrm{m}} \mathrm{F}_{2}$ values from ionosonde observations at Wuhan station and compared these with those inverted by GPS-based tomographic reconstruction. The peak density $\mathrm{N}_{\mathrm{m}} \mathrm{F}_{2}$ and the peak height $\mathrm{h}_{\mathrm{m}} \mathrm{F}_{2}$ obtained from the ionosonde observations and the CIT technique during the 24 hours of 18 August 2003 are shown in Figs. 3 and 4, respectively. The comparisons show that the agreement between the results from the ionosonde data and the tomographic reconstruction is generally very good, thereby confirming that a reasonable IED distribution can be reconstructed using the IRI model-assisted GPS-based CIT.
Although the IED image can be satisfactorily reconstructed with the IRI model-assisted GPS-based CIT, some differences between the true image and the reconstructed image still exist. The differences may be attributed to the following factors: experimental measurement error, the errors caused by various approximations and assumptions made on the projection operator, discretized error of the image region, and the errors induced from IRI model and the ideal geometry or conditions, among others.

\section{Discussion and Conclusion}

In this work, a GPS-based CIT technique is applied to study the ionospheric response to the magnetic storm on that occurred on 18 August 2003. The IED image reconstructed using the GPS observations from CMONOC show that a prominent large-scale ionospheric disturbance is evident in the China sector with an ionization enhancement at low-latitude regions and ionization depletion at midlatitudes, which represent the positive and negative storm phase effects, respectively. Similar to the previous theoretic analyses by Buonsanto (1999) and the references therein, the negative storm phases that occurred in mid-latitude during the geomagnetic storm on 18 August 2003 could be attributed to an increased input of energy to the region and an expansion of the neutral atmosphere. Such a rapid expansion may cause upwelling, which induces a dramatic depletion of the atomic to molecular neutral density ratio. This change in chemical composition causes increased recombination in the ionosphere and a reduction in ionization concentration (Yizengaw et al., 2004). The positive phases are generally believed to be caused by uplifting of the F-region by equatorward winds in the early stage of a storm development. (Cander and Mihajlovic, 2005; Lin et al., 2005; Yizengaw et al., 2005).

The reconstructed results suggest that one may monitor and investigate the disturbed variations of the IED over China during a geomagnetic storm with the CIT method used in this work and dual-frequency GPS phase data from the CMONOC. This approach will facilitate studies aimed at improving our understanding of the finer structures of the ionosphere during magnetic storms. The tomographic results illustrate that the intense disturbance of the ionosphere over China occurred during the storm and that the ionospheric storm phase effects are not only latitude-dependent but also altitude-dependent. The positive storm phase effects occurred between $10^{\circ} \mathrm{N}$ and $35^{\circ} \mathrm{N}$, the negative storm phase effect occurred latitudinally from $35^{\circ} \mathrm{N}$ and and $55^{\circ} \mathrm{N}$ altitudinally from 200 and $600 \mathrm{~km}$ above the ground.

These results provide valuable insights into the characteristics and variation mechanism of the ionosphere during geomagnetic storms, and they are capable of providing a valuable experimental support for understanding the complex behavior of the low-latitude F-region during geomagnetic storms.

Acknowledgments. The authors would like to thank the data center of the Crustal Movement Observation Network of China for providing the ground-based GPS tracking station data. Professor Libo Liu from the Institute of Geology and Geophysics of Chinese Academy of Sciences is also especially thanked for providing ionosonde data. This research is supported by the National 
Science Fund for Distinguished Young Scholars of China (Grant No. 40625013) and the National Natural Science Foundation of China (Grant No. 40674012 and No. 40474009).

\section{References}

Austen, J. R., S. J. Franke, C. H. Liu, and K. C. Yeh, Application of computerized tomography technique to ionospheric research, in URSI and COSPAR International Beacon Satellite Symposium on Radio Beacon Contribution to the Study of Ionization and Dynamics of the Ionosphere and to Corrections to Geodesy and Technical Workshop, Oulu, Finland, edited by A. Tauriainen, Proc Part I, 25, 1986.

Blewitt, G., An automatic editing algorithm for GPS data, Geophys. Res. Lett., 17, 199-202, 1990.

Buonsanto, M. J., Ionospheric storms-a review, Space Sci. Rev., 88, 563601, 1999.

Bust, G. S., D. Coco, and J. J. Makela, Combined ionospheric campaign 1: Ionospheric tomography and GPS total electron content (TEC) depletions, Geophys. Res. Lett., 27, 2849-2852, 2000.

Hernandez-Pajares, M., J. M. Juan, and J. Sanz, Global observation of ionospheric electronic response to solar events using ground and LEO GPS data, J. Geophys. Res., 103, 20789-20796, 1998.

Jakowski, N., E. Sardon, E. Engler, A. Jungstand, and D. Klahn, Relationship between GPS-signal propagation errors and EISCAT observations, Ann. Geophys., 14, 1429-1436, 1996.

Kunitsyn, V., E. Tershchenko, and E. Andreeva, Radiotomographic investigations of ionospheric structures at auroral and middle latitudes, Ann. Geophys., 12, 1242-1253, 1995.

Kunitsyn, V., E. Andreeva, and O. Razinkov, Possibilities of the near-space environment radio tomography, Radio Sci., 32, 1953-1963, 1997.

Leitinger, R., H.-P. Ladreiter, and G. Kirchengast, Ionospheric tomography with data from satellite reception of Global navigation satellite system signals and ground reception of navy navigation satellite system signals, Radio Sci., 11, 1657-1669, 1997.

Liu, C. H., A. D. Richmond, J. Y. Liu, H. C. Yeh, L. J. Paxton, G. Lu, H. F. Tsai, and S.-Y. Su, Large-scale variations of the low-latitude ionosphere during the October-November 2003 superstorm: Observational results, J. Geophys. Res., 110, doi:10.1029/2004JA010900, 2005.

Cander, L. R. and S. J. Mihajlovic, Ionospheric spatial and temporal variations during the 29-31 October 2003 storm, J. Atmos. Sol. Terr. Phys., 67, 1118-1128, 2005.

Ma, X. F. and T. Maruyama, Three-dimensional Ionospheric tomography using observation data of GPS ground receiver and ionosonde by neural network, J. Geophys. Res., 110, doi:10.1029/2004JA010797, 2005.

Pryse, S. E., L. Kersley, and C. N. Mitchell, A comparison of reconstruction techniques used in ionospheric tomography, Radio Sci., 33, 17671779, 1998.

Rius, A., G. Ruffini, and L. Cucurull, Improving the vertical resolution of ionospheric tomography with GPS occultation, Geophys. Res. Lett., 24, 2291-2294, 1998.

Raymund, T. D., J. R. Austen, and S. J. Franke, Application of computerized tomography to the investigation of ionospheric structure, Radio Sci., 25, 771-789, 1990.

Wen, D. B., Y. B. Yuan, J. K. Ou, X. L. Huo, and K. F. Zhang, Threedimensional ionospheric tomography by an improved algebraic reconstruction technique, GPS Solut., DOI 10.1007/s10291-007-0055-y, 2007.

Yang, Y. and S. Zhang, Adaptive fitting of systematic errors in navigation, J. Geod., 79, 43-49, 2005.

Yin, P. and C. N. Mitchell, Ionospheric electron concentration imaging using GPS over USA during the storm of July 2000, Geophys. Res. Lett., 31, doi:10.1029/2004GL019899, 2004.

Yin, P. and C. N. Mitchell, Use of radio occultation data for ionospheric imaging during the April 2003 disturbances, GPS Solut., 9, 156-163, 2005.

Yizengaw, E., E. A. Essex, and R. Birsa, The southern hemisphere and equatorial region ionization response for a 22 September 1999 severe magnetic storm, Ann. Geophys., 22, 2765-2773, 2004.

Yizengaw, E., P. L. Dyson, E. A. Essex, and M. B. Moldwin, Ionosphere dynamics over the southern Hemisphere during the 31 March 2001 severe magnetic storm using multi-instrument measurement data, Ann. Geophys., 23, 707-721, 2005.

Yuan, Y. B. and J. K. Ou, The effects of instrumental bias in GPS observations on determining ionospheric delays and the methods of its calibration, Acta Geodaet, Cartograph. Sinica, 28, 110-114, 1999.

Yuan, Y. B., D. B. Wen, J. K. Ou, X. L. Huo, R. G. Yang, K. F. Zhang, and R. Grenfel, Preliminary research on imaging the ionosphere using CIT and China permanent GPS tracking station data, in Dynamic Planet: Monitoring and Understanding a Dynamic Planet with Geodetic and Oceanographic Tools, edited by P. Tregoning and C. Rizos, 876 pp., 2005 .

D. B. Wen, Y. B. Yuan (wdbwhigg@hotmail.com), J. K. Ou, X. L. Huo, and K. F. Zhang 